\title{
Einbände mit sichtbarem Inhalts- oder Provenienzbezug
}

Auf der Ludwigsburger Antiquariatsmesse 2013 konnten mehrere Bände mit bemerkenswerten Einbänden erworben werden. Gemeinsam ist innen, dass die Art der Einbandgestaltung auf den Inhalt bzw. den Vorbesitzer hinweist.

Die 1846 in London erschienene Ausgabe der mediävistischen Untersuchung "Historical pictures of the middle ages in black and white" von Alicia Moore (WLB-Signatur 63/90003) ist mit einem Prämienband aus grünem Maroquin eingebunden. Als Preis für besondere Leistungen an höheren Schulen oder Universitäten werden seit dem 17. Jahrhundert zunächst in den Beneluxländern und Frankreich, später auch in England und Deutschland eigens aus diesem Anlass gebundene Bücher übergeben. Die Widmung bzw. Übergabebestätigung befindet sich meist als handschriftlicher Eintrag oder beigeheftete Seite am Anfang des Buchblocks, während die verleihende Institution auf dem Vorderdeckel angedeutet wird. Die goldgeprägten Einträge auf dem Vorderdeckel identifizieren Ort, Zeit und wahrscheinlich eher die Institution als die Empfängerin der Auszeichnung. Rose Mount ist als Teilort von Ledbury, Herefordshire, vermutlich Namensbestandteil der dort ansässigen Sekundarschule, nicht der Name der geehrten Schülerin. Eine ursprünglich beigeheftete Urkunde ist herausgerissen. Die Deckel verfügen über doppelt blind- bzw. goldgeprägte Fileten als Rahmen und ein goldgeprägtes Medaillon mit geometrischer bzw. stark stilisierender floraler Ornamentik. Florale Muster sind deutlicher erkennbar auf der goldgeprägten filigranen Innenkantenverzierung sowie insbesondere in den detailliert ausgestalteten Rückenfeldern. Ein gewisser Eklektizismus, also die Kombination historischer Stilelemente aus ganz unterschiedlichen Kontexten, ist nicht untypisch für Einbände des 19. Jahrhunderts. Ausdruck englischer Zurückhaltung ist die im 17. Jahrhundert auf den britischen Inseln entwickelte Form der Schnittbemalung. Als "Fore-edge

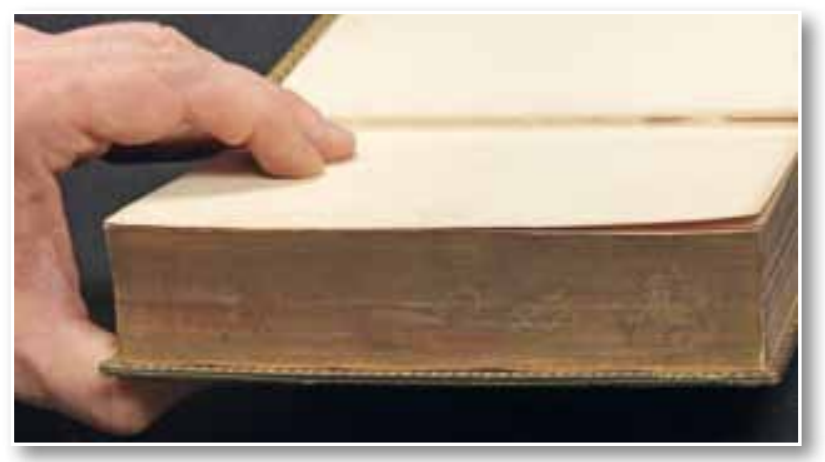

Painting" kommt das Miniaturgemälde unter dem Goldschnitt erst dann zum Vorschein, wenn man diesen etwas verschiebt. Häufig ist das Motiv auf den Inhalt des Buches bezogen. So sind auf dem vorliegenden Schulpreisband aufeinander zureitende Ritter mit Lanzen auf einer Waldlichtung zu erkennen. Zur dezenten Verzierung des Einbands und zur Thematisierung ehrenhaften Verhaltens anhand des Rittermotivs passt die zentrale Figur der historischen Erzählung. Bertha von Schwaben (ca. 907-966) ist auf einem lithographierten Frontispiz zu sehen. Bertha gilt in der Folgezeit als Vorbild in der Bewältigung ihrer Aufgaben als Herrscherin und Hausfrau. So übt das Buch in seiner Gesamtkomposition eine erzieherische Wirkung auf die Empfängerin aus und vermittelt auf ganzheitliche Weise Lehrinhalte in der Schule.

Ein weiteres Beispiel englischer Einbandkunst ist ein Exemplar des anglikanischen „Book of Common Prayer", Oxford 1801 (63/90001). Auf dem Schnitt des blauen Maroquin-Bändchens mit goldgeprägter Bordüre im Etruscan Style ist hier für England charakteristisch - ein Landschaftsbild mit Ortschaft und Kirche im Stil englischer Gotik verborgen. Die aktive Teilnahme am stark liturgisch und ästhetisch geprägten Gottesdienst der Church of England bedeutet wegen des national- bzw. staatskirchlichen Charakters immer auch eine Identifikation mit Land, Kultur und Volk. Der Einband bringt diese spezifisch englische Einheit kulturellkünstlerischer, religiöser und nationaler Haftpunkte von Identität zum Ausdruck. 


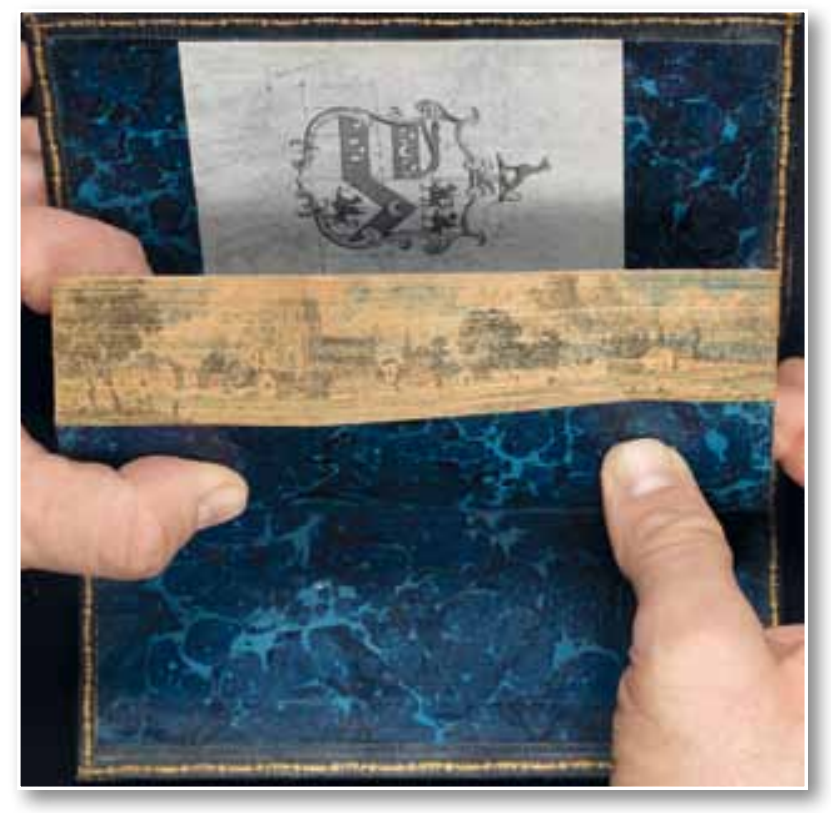

Ein Werk über die Entwicklung von Ideen bzw.

40 Wertüberzeugungen in der Moralphilosophie, zumal als deutscher Druck in französischer Sprache, passt gut in die Privatbibliothek eines Herrschers (63/90002). ${ }^{1}$ Inhalt und Provenienz sind einander eindeutig zugeordnet durch Elemente regionaler Symbolik auf dem Einband. Das kalligraphisch gestaltete Monogramm mit dem Buchstaben W samt Krone in Goldprägung weist einen grünen Maroquin-Einband als Besitz des württembergischen Königs Wilhelm I. (1781-1864, König ab 1816) aus. Auf dem Rückdeckel ist das seit 1817 gebräuchliche Wappen Württembergs zu sehen. Zur bibliophilen Gestaltung des Buches tragen auch die goldgeprägten Bordüren bzw. Fileten sowie Goldschnitt und Spiegelblätter aus Wurzelmarmorpapier bei.

Christian Herrmann

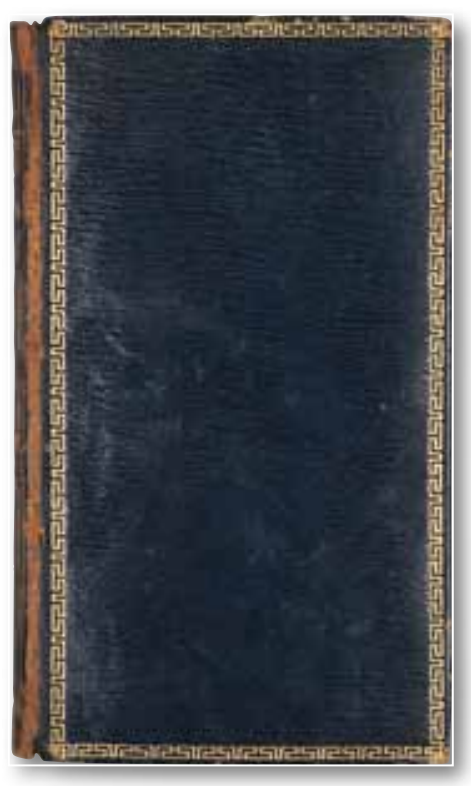

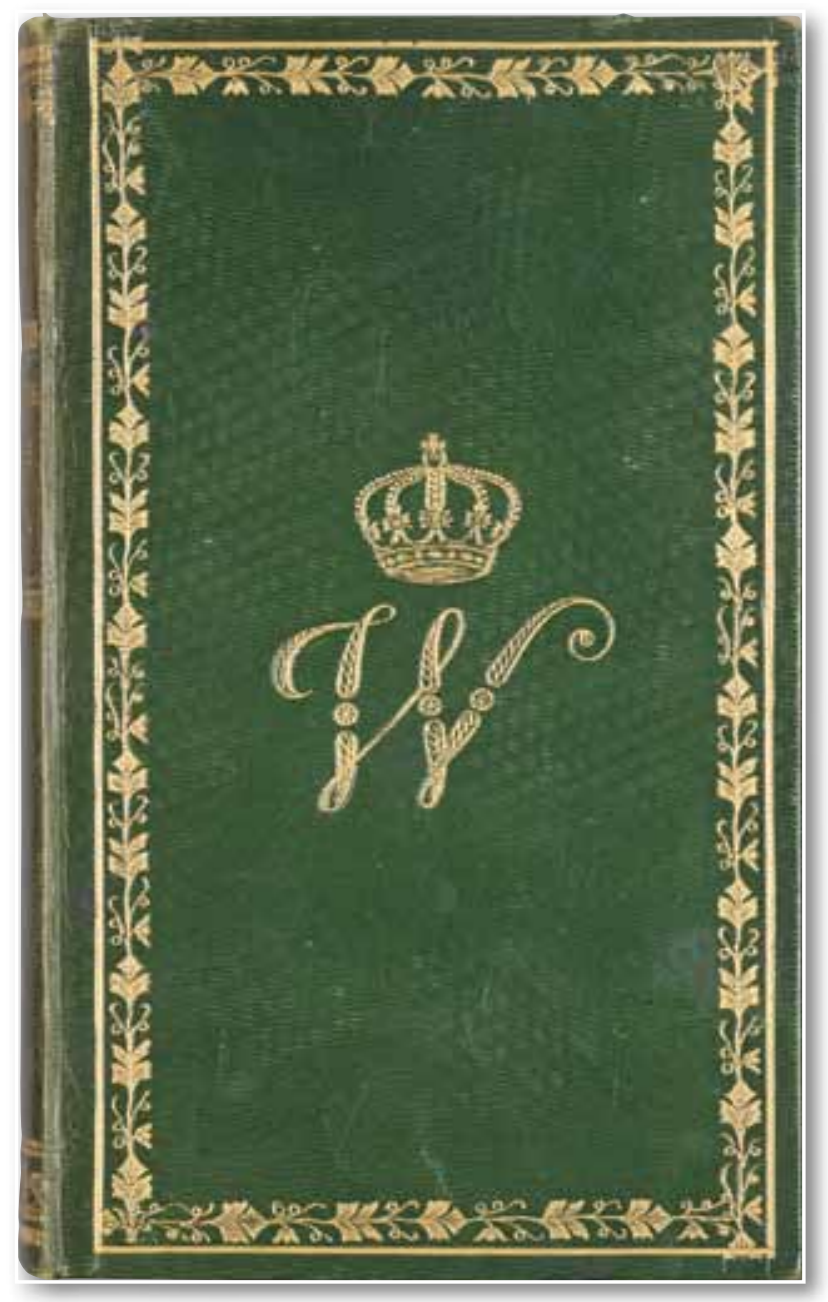

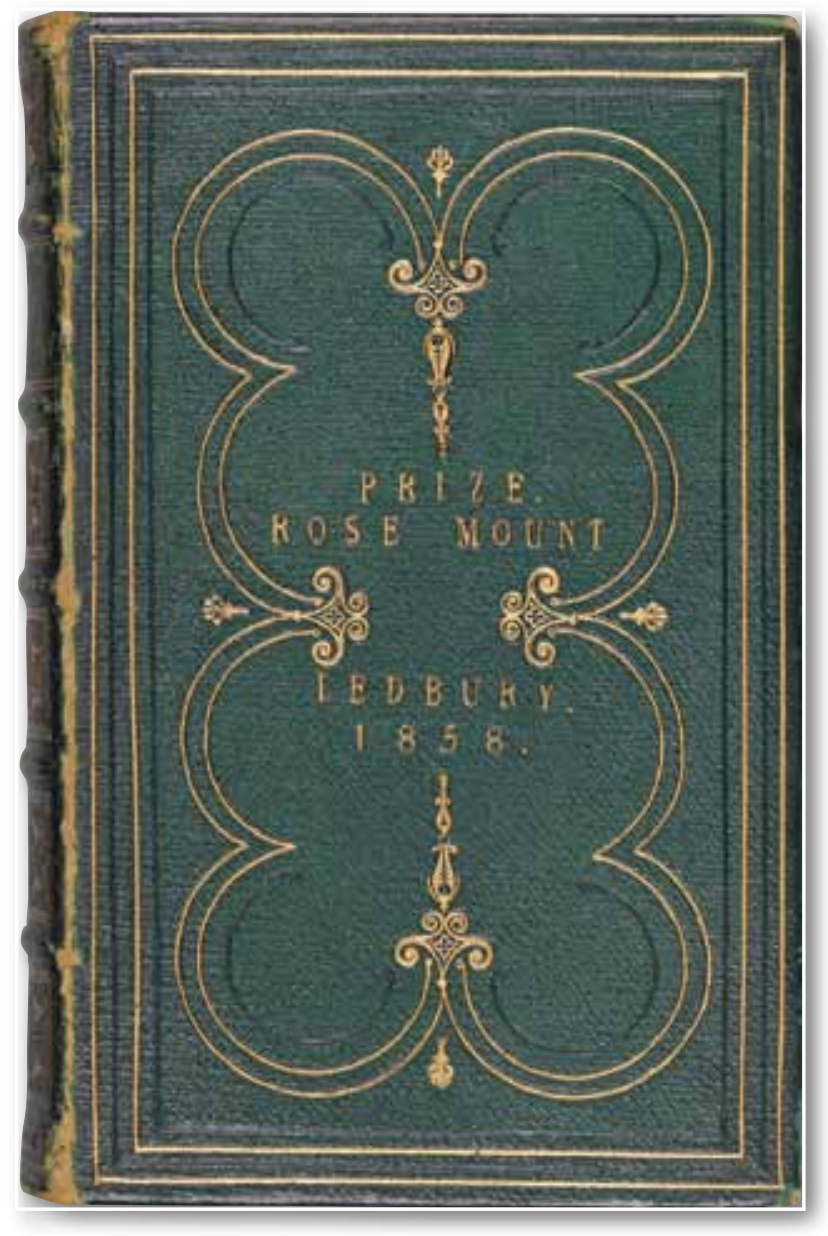

(1) Toussaint, N. J. B., De la nécessité des signes pour la formation des idées et de divers sujets de philosophie morale, Stouttgart \& Tubingue: Cotta, 1827. 